\title{
Printability and Properties of 3D-printed Poplar Fiber/Polylactic Acid Biocomposite
}

\begin{abstract}
Zhaozhe Yang, ${ }^{\mathrm{a}, \mathrm{b}}$ Xinhao Feng, ${ }^{\mathrm{b}, *}$ Min $\mathrm{Xu},{ }^{\mathrm{c}}$ and Denis Rodrigue ${ }^{\mathrm{d}}$
To efficiently and economically utilize a wood-plastic biocomposite, an eco-friendly biocomposite was prepared using modified poplar fiber and polylactic acid (PLA) via 3D printing technology for the first time. First, the effects of poplar fiber $(0,1,3,5,7$, and $9 \%)$ on the mechanical and rheological properties of the printed biocomposites were investigated. Subsequently, the printing parameters, including printing temperature, speed, and layer thickness, were optimized to obtain the biocomposite with superior properties. Finally, four printing orientations were applied to the biocomposite based on the optimized printing parameters to study the effect of filament orientation on the properties of the biocomposite. Favorable printability and mechanical properties of the biocomposite were obtained at $5 \%$ poplar fiber. The optimal printing temperature of $220^{\circ} \mathrm{C}$, speed of $40 \mathrm{~mm} / \mathrm{s}$, and layer thickness of $0.2 \mathrm{~mm}$ were obtained to produce the desired mechanical properties of the biocomposite with the printing orientation in a longitudinal stripe. However, the printing parameters should be chosen according to the applications, where different physical and mechanical properties are needed to achieve efficient and economical utilization of the biocomposites.
\end{abstract}

Keywords: Poplar fiber; Polylactic acid; 3D Printing; Biocomposite; Rheology

Contact information: a: Chinese Academy of Forestry, Institute of Chemistry and Industry of Forest Products, Nanjing, Jiangsu 210042 China; $b$ : Nanjing Forestry University, College of Furnishings and Industrial Design, Nanjing, Jiangsu 210037 China; c: Northeast Forestry University, College of Material Science and Engineering, Harbin, Heilongjiang 150040 China; d: University of Laval, Department of Chemistry and Engineering, Quebec City, PQ GIV OA6 Canada;

*Corresponding author: fengxinhao@ hotmail.com

\section{INTRODUCTION}

As a 3D printing technology, fused deposition modeling (FDM) is commonly applied to fabricate complex and customized structures with high efficiency and low cost. It has been extensively used in prototyping and product manufacturing for many applications such as automatization, construction, biological engineering, and furniture (Wang et al. 2017; Zhao et al. 2018; Oladapo et al. 2020; Zeng et al. 2020). However, the raw material for FDM is limited to thermoplastics, including acrylonitrile butadiene styrene (ABS), nylon, polycarbonate, polyethylene, and polylactic acid (PLA) (Le Duigou et al. 2016). With increasing attention paid directly towards eco-friendly materials, bio-based polymers (e.g. PLA) are preferred during 3D printing. Polylactic acid is mainly derived from renewable resources, such as starch, corn, and sugarcane, and it is biodegradable, biocompatible, widely available commercially, and possesses relatively high material properties (Guo et al. 2014; Chacon et al. 2019; Liu et al. 2019). Therefore, 3D printed PLA has been applied for tissue engineering (Yu et al. 2019; Oladapo et al. 2020), electronics (Spinelli et al. 2019), thermal and sound absorbing materials (Papon and Haque 
2018), and construction (Hinchcliffe et al. 2016; Ghaffar et al. 2018). In addition, 3Dprinted PLA products can be recycled and reprinted to fabricate structures, which have comparable properties with the one before recycling (Tian et al. 2017; Zhao et al. 2018).

However, PLA is brittle and has a low thermal resistance, resulting in restricted applications in load-bearing and functional structures (Yang and Yeh 2020). Accordingly, natural resources, such as wood fibers (Le Duigou et al. 2016; Kain et al. 2020), nanocellulose (Wang et al. 2017; Liu et al. 2019), and agriculture residuals (Hinchcliffe et al. 2016; Xiao et al. 2019), which possess high mechanical properties, good sustainability, non-toxicity, biocompatibility, and biodegradability, have been incorporated with PLA to 3D print biocomposites used in construction, tissue engineering, packaging, furniture, etc. (Dong et al. 2018; Xu et al. 2018; Yang et al. 2020).

Generally, the processing property of 3D-printed PLA biocomposites is affected by natural fibers because a specific melt flow rate of the filament is needed during 3D printing (Wang et al. 2017; Papon and Haque 2018). The incorporation of natural fibers in the polymer matrix induces increased viscosity of the fused compound and results in low filament properties and weak interfacial bonding between fiber and polymer matrix (Ayrilmis 2018; Nguyen et al. 2018; Ghaffar et al. 2020). Therefore, additives (e.g., coupling, toughening agents, and nano graphite platelet) were added in the compound to improve the processability and properties of 3D-printed biocomposites (Wang et al. 2017; Papon and Haque 2018; Chougan et al. 2020). In addition, surface modification of the natural fibers can also enhance their compatibility with PLA matrix and improve the properties of 3D-printed products (Filgueira et al. 2017; Murphy and Collins 2018).

To improve the compatibility of poplar fiber with PLA matrix during extrusion, and to overcome the brittleness of the corresponding biocomposites, the modification of poplar fiber by silane coupling agent (3-aminopropyltriethoxysilane, KH550) and the toughening agent tributyl citrate (TBC) was taken to produce a biocomposite with superior mechanical properties and toughness, respectively (Yang et al. 2019, 2020). However, few studies have been made to explore the possibility of the poplar fiber/PLA biocomposite as a raw material applied in 3D printing, especially for the modified biocomposite (Bhagia et al. 2020). Therefore, it is imperative to investigate the printability and properties of 3D-printed poplar fiber/PLA biocomposite to extend the application of the poplar fiber/PLA biocomposite. In this study, the printability of 3D-printed poplar fiber/PLA biocomposites with various amounts of poplar fiber $(0,1,3,5,7$, and $9 \%)$ was investigated at the printing temperature of $220{ }^{\circ} \mathrm{C}$, speed of $20 \mathrm{~mm} / \mathrm{s}$, and thickness of $0.2 \mathrm{~mm}$. Subsequently, the optimal content of poplar fiber was selected based on the optimal mechanical and rheological of printed biocomposites in the first step, and the effect of printing parameters on the properties of the corresponding biocomposite was then thoroughly analyzed.

\section{EXPERIMENTAL}

\section{Materials}

The PLA was supplied by Nature Works (4032D; Minnetonka, MN, USA). The provided PLA had a density of $1.25 \mathrm{~g} / \mathrm{cm}^{3}$, a melting temperature of $167{ }^{\circ} \mathrm{C}$, and a melting flow index of $1 \mathrm{~g} / \mathrm{min}\left(210^{\circ} \mathrm{C} / 2.16 \mathrm{~kg}\right)$. Poplar fiber with the average dimensions $293 \times$ $62 \mathrm{~m}^{2}$ (length $\times$ width) was self-produced in the lab from poplar wood (Populus adenopoda). Briefly, poplar chips were added in a wood grinder equipped with a screen (9FQ-300; Zhengda Agricultural Machinery Manufacturing Co., Ltd., Dandong, China), 
and the fiber was collected from the 80-mesh screen to be directly used in biocomposite production. The KH550 and TBC were provided by the Yongchang Chemical Company (Harbin, China). All chemicals were used as received.

\section{Filament Extrusion}

The poplar fiber modified with KH550, as described in a previous study (Yang et al. 2020), was compounded with PLA and TBC to prepare the pellets used in filament extrusion (Fig. 1a). The pellets were extruded by a single screw extruder at $170{ }^{\circ} \mathrm{C}$ with an extruding and traction speed of $45 \mathrm{rpm}$ and $27 \mathrm{rpm}$, respectively. The contents of poplar fiber in the filament were $0,1,3,5,7$, and $9 \%$, and the diameter of the filament was $1.75 \mathrm{~mm}$. The process of filament extrusion is shown in Fig. 1a.

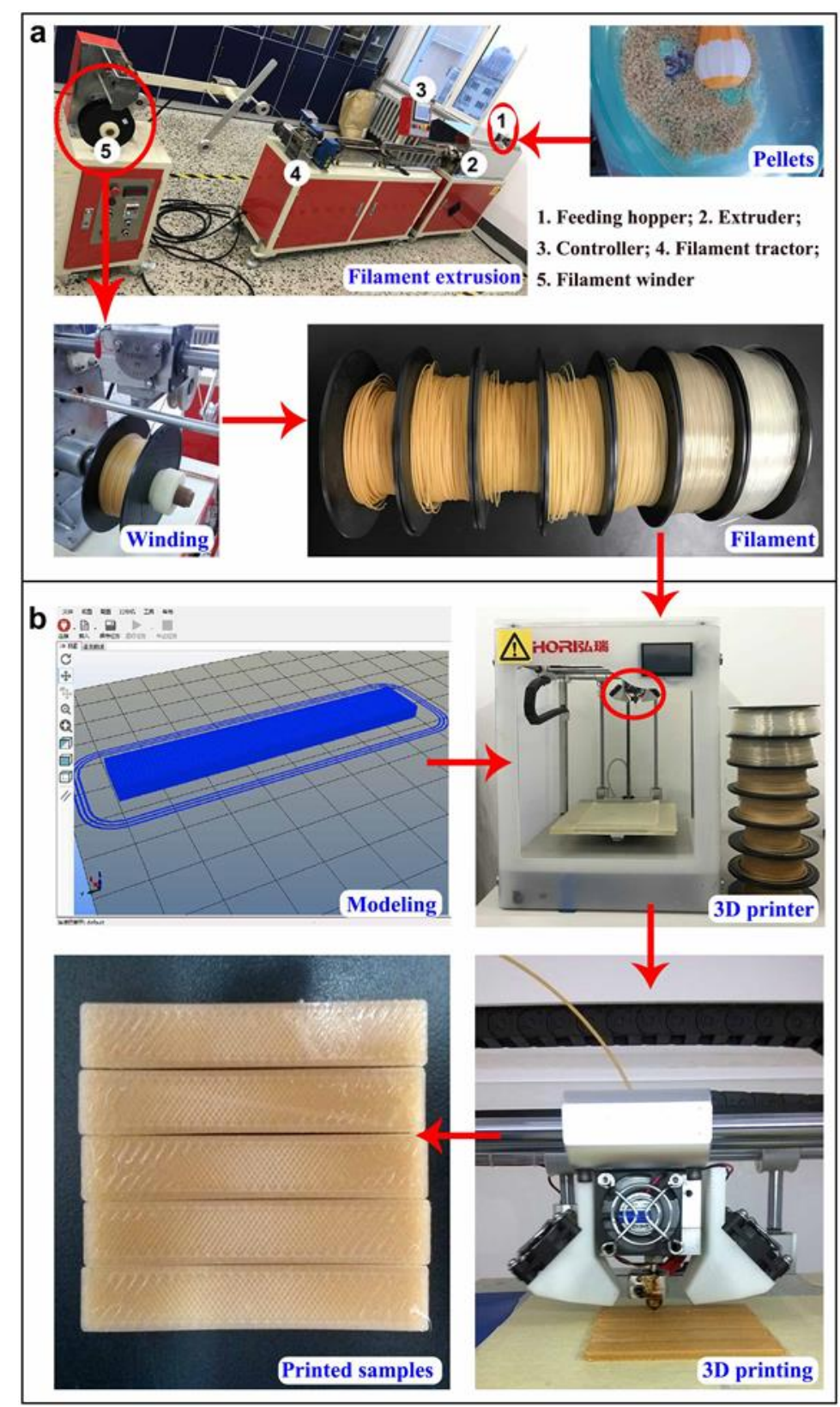

Fig. 1. The process of filament extrusion, $a$; and 3D printing sample, $b$ 


\section{D Printing of the Poplar Fiber/PLA Biocomposites}

As shown in Fig. 1b, the poplar fiber/PLA biocomposite was fabricated by a 3D printer with the filament. Before 3D printing, a model of the sample was prepared using AutoCAD (AutoCAD, Autodesk Inc., AutoCAD2015, San Rafael, CA, USA), and the printing parameters of the model were set and exported as a G-code file for use in the 3D printer (Fig. 1b). During 3D printing, firstly, the filament was printed at a fixed temperature, speed, and thickness of $220{ }^{\circ} \mathrm{C}, 20 \mathrm{~mm} / \mathrm{s}$, and $0.2 \mathrm{~mm}$, respectively, to investigate the printability of the biocomposite with different contents of poplar fiber $(0,1$, $3,5,7$, and 9\%); subsequently, the biocomposite with the optimal content of poplar fiber obtained in the previous step was printed under different printing conditions, as shown in Table 1, to analyze the effect of the printing conditions (i.e., temperature, speed, and layer thickness) on the properties of the printed biocomposites. The optimized printing conditions were indicated.

Table 1. Printing Parameters of Modified Poplar Fiber/PLA Biocomposites

\begin{tabular}{|c|c|c|}
\hline Printing Parameter & Variable Parameter & Fixed Parameter \\
\hline Temperature $(\mathrm{T})\left({ }^{\circ} \mathrm{C}\right)$ & $200,210,220,230,240$ & $\mathrm{~L}: 0.2 \mathrm{~mm}, \mathrm{~S}: 20 \mathrm{~mm} \times \mathrm{S}^{-1}$ \\
\hline Printing speed $(\mathrm{S})\left(\mathrm{mm} \times \mathrm{s}^{-1}\right)$ & $20,40,60,80,100$ & $\mathrm{~L}: 0.2 \mathrm{~mm}, \mathrm{~T}: 220^{\circ} \mathrm{C}$ \\
\hline Printing thickness $(\mathrm{L})(\mathrm{mm})$ & $0.1,0.2,0.3,0.4,0.5$ & $\mathrm{~S}: 20 \mathrm{~mm} \times \mathrm{S}^{-1}, \mathrm{~T}: 220^{\circ} \mathrm{C}$ \\
\hline
\end{tabular}

\section{Characterizations}

The tensile and flexural properties of the biocomposites were measured using a universal mechanical tester (ReGear, Shenzhen, China) with the sample dimensions $165 \times$ $13 \times 4 \mathrm{~mm}^{3}$ and $80 \times 13 \times 4 \mathrm{~mm}^{3}$, according to ASTM D638-14 (2014) and ASTM D79017 (2017), respectively. The testing speed for tensile and flexural measurements were $5 \mathrm{~mm} / \mathrm{min}$ and $1.9 \mathrm{~mm} / \mathrm{min}$ (with a span of $64 \mathrm{~mm}$ ), respectively. Six replicates were measured in each condition.

The surface morphology of the printed biocomposites was observed by a scanning electron microscope (FEI Quanta 200; FEI Co., Hillsboro, OR, USA) at an accelerating voltage of $10 \mathrm{kV}$ and a working distance of 8 to $12 \mathrm{~mm}$. Samples were dried at $80{ }^{\circ} \mathrm{C}$ for $2 \mathrm{~h}$ and gold sputtered for $10 \mathrm{~s}$ before the scanning.

The thermal stability of the biocomposites was analyzed using a thermogravimetric analyzer (TGA, TA4; NETZSCH, Bavaria, Germany). A sample of approximately $5 \mathrm{mg}$ was loaded and heated from $40{ }^{\circ} \mathrm{C}$ to $600{ }^{\circ} \mathrm{C}$ at $10{ }^{\circ} \mathrm{C} / \mathrm{min}$ in a nitrogen atmosphere $(50 \mathrm{~mL} / \mathrm{min})$. Three replicates were used for each condition.

The thermal behavior of the biocomposite was performed in a differential scanning calorimeter (DSC, Q20; TA Instruments, New Castle, DE, USA). Three temperature scans were taken according to the method that has been reported in the authors' previous study (Yang et al. 2020). The temperatures of the glass transition $\left(T_{\mathrm{g}}\right)$, crystallization $\left(T_{\mathrm{c}}\right)$, and melting $\left(T_{\mathrm{m}}\right)$ of the biocomposites were analyzed based on the results of endothermic and exothermic reactions during the second heating scan.

The dynamic rheological properties of the biocomposites were investigated with a rotational rheometer (Discovery HR-2; TA Instruments, New Castle, DE, USA). Firstly, a dynamic strain sweep $(0.001$ to $100 \%)$ was measured at $190{ }^{\circ} \mathrm{C}$ with an angular frequency of $6.283 \mathrm{rad} / \mathrm{s}$ to determine the linear viscoelastic region of the biocomposite. Then, a dynamic frequency sweep (0.06 to $628.3 \mathrm{rad} / \mathrm{s}$ ) was performed at $190{ }^{\circ} \mathrm{C}$ with a constant strain of $1 \%$. Three replicates were used in each condition. 


\section{RESULTS AND DISCUSSIONS}

\section{Effect of Poplar Fiber on the Properties of Printed Biocomposites}

The flexural strength and modulus of the printed biocomposites increased as the fiber content was increased from $0 \%$ to $5 \%$ and decreased when the fiber content exceeded $5 \%$ (Fig. 2a and 2c). This could be attributed to the improved dispersibility of poplar fiber in the PLA matrix, which results from the improved compatibility between poplar fiber and PLA after the KH550 modification of poplar fiber (Yang et al. 2020). However, high fiber content $(>5 \%)$ would decrease the thermal conductivity between printed layers due to the poor thermal conductivity of poplar fiber; especially, lumens in the poplar fiber contribute to decrease of heat transferring in the printed layers (Liu et al. 2014), which resulted in weak interfacial bonding between printed layers and a decrease of flexural properties (Tian et al. 2016).
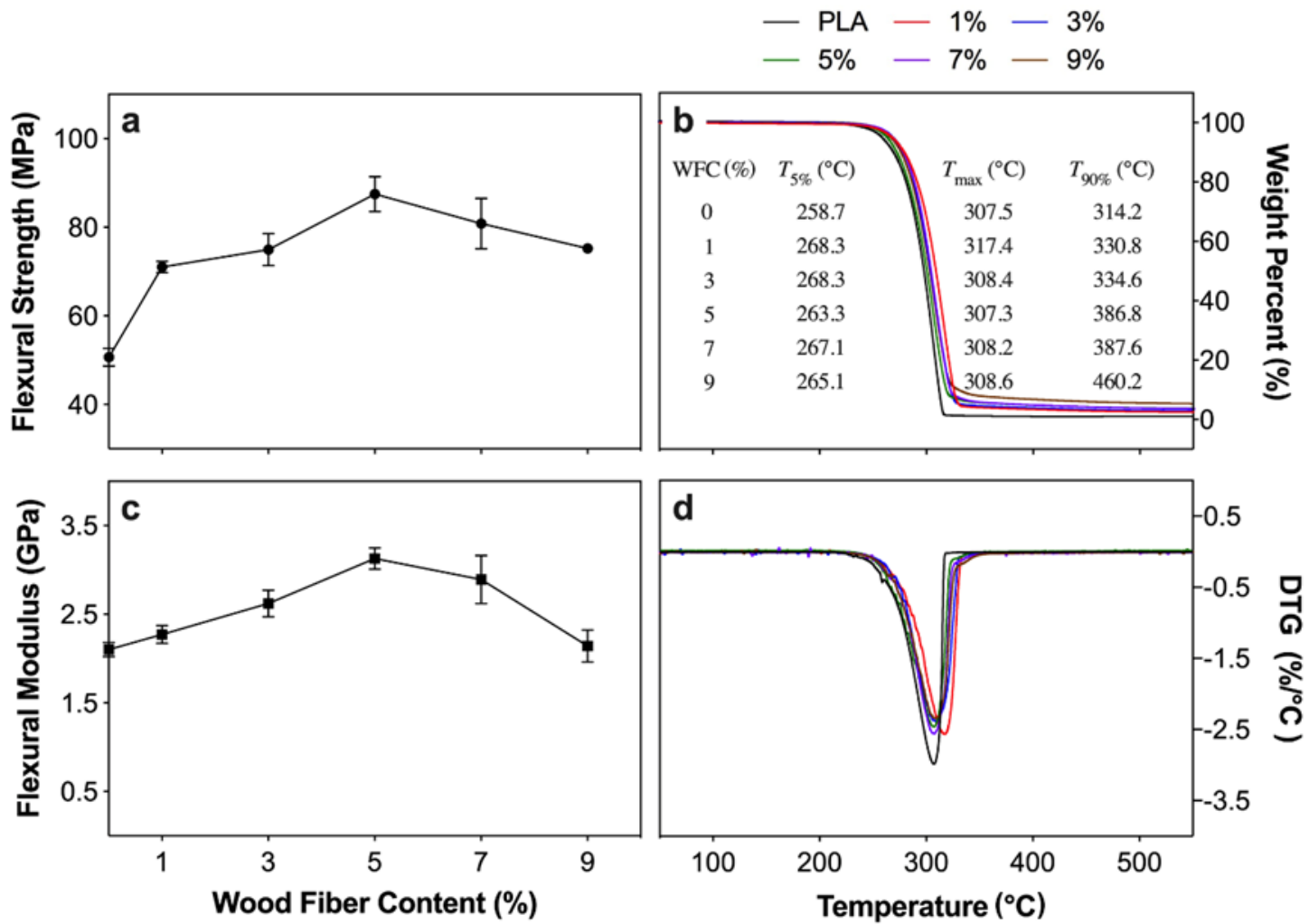

Fig. 2. The flexural properties $(a=$ strength; $c=$ modulus $)$ and thermal stability $(b=T G ; d=D T G)$ of 3D-printed biocomposites with increasing wood fiber content (WFC) ( $T_{5 \%}, T_{\max }$, and $T_{90 \%}$ represent the temperature at $5 \%$ weight loss, weight loss at maximum speed, and $90 \%$ weight loss during thermogravimetric testing, respectively)

The thermal stability of the printed biocomposites was enhanced with the addition of poplar fiber (Figs. $2 \mathrm{~b}$ and $2 \mathrm{~d})$. The temperature at initial $\left(T_{5} \%\right.$, temperature at $5 \%$ weight loss), peak ( $T_{\max }$, temperature for the weight loss at maximum speed), and end ( $T_{90 \%}$, temperature at $90 \%$ weight loss) of the thermal degradation of the biocomposite with $1 \%$ poplar fiber increased $9.6{ }^{\circ} \mathrm{C}, 9.9{ }^{\circ} \mathrm{C}$, and $16.6^{\circ} \mathrm{C}$, respectively, compared to pure PLA samples. However, this progressive increase leveled off with further additions of poplar fiber from 3 to $9 \%$, especially for the $T_{5} \%$ and $T_{\max }$. However, the $T_{90 \%}$ still had a $39 \%$ 
increase for the biocomposite with $9 \%$ poplar fiber compared to that of biocomposite with $1 \%$ poplar fiber. When the amount of poplar fiber increased, the temperature for the glass transition $\left(T_{\mathrm{g}}\right)$ of the biocomposite slightly increased from $1 \%$ to $5 \%$ and decreased from $7 \%$ to $9 \%$. While, the crystalized temperature $\left(T_{\mathrm{c}}\right)$ and melting temperature $\left(T_{\mathrm{m}}\right)$ did not linearly increase with increasing content of poplar fiber, they exhibited a decrease from $1 \%$ to $5 \%$ and increase from $5 \%$ to $9 \%$, and minimum values were obtained at 5\% (Fig. 3). The increased $T_{\mathrm{c}}$ was caused by the orientation of poplar fibers during $3 \mathrm{D}$ printing, resulting in an improved bonding likelihood between poplar fibers and between poplar fiber and PLA molecules (Compton and Lewis 2014). As for the increased $T_{\mathrm{m}}$, it could be attributed to the enhanced compatibility between the poplar fiber and PLA matrix after KH550 modification; additionally, the introduced KH550 molecules would impede the mobility of fused molecules due to its high steric hindrance generated in the biocomposite (Li et al. 2003).

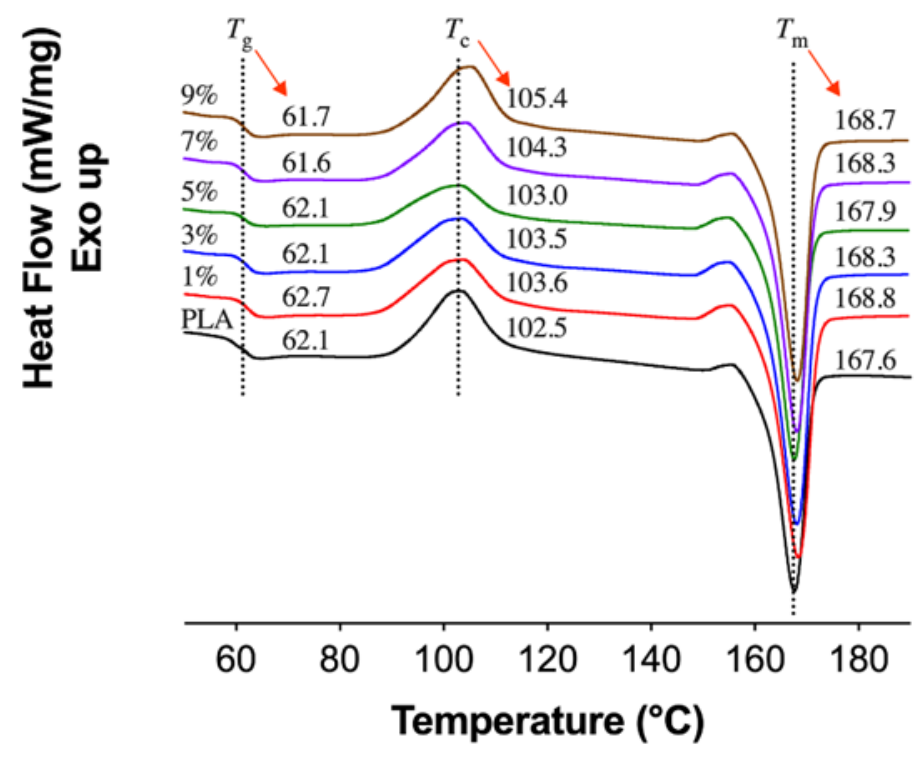

Fig. 3. The thermal performance of 3D-printed biocomposites with 0 (pure PLA), 1, 3, 5, 7, and $9 \%$ wood fiber $\left(T_{\mathrm{g}}, T_{\mathrm{c}}\right.$, and $T_{\mathrm{m}}$ are the temperatures for glass transition, crystallization, and melting of the biocomposite, respectively)

From the dynamic strain sweep (Fig. 4a), the storage modulus $\left(G^{\prime}\right)$ was retained with increasing strain between $0.5 \%$ and $6 \%$ (Fig. 4a), indicating a linear viscoelastic state was generated in the biocomposite. Therefore, the strain of $1 \%$ was chosen in the dynamic frequency sweep. The storage modulus of the biocomposite was frequency-independent at low frequency from $0.1 \mathrm{~Hz}$ to $1 \mathrm{~Hz}$ (Fig. 4c). This was probably due to the gap between the printed filaments where the fused biocomposite filled in during the frequency sweep. Meanwhile, at a fixed frequency (in range of 0.1 to $1 \mathrm{~Hz}$ ), the storage modulus increased with increase of poplar fiber due to the high rigidity of poplar fiber in the biocomposite. At high frequencies $(>1 \mathrm{~Hz})$, the storage and loss modulus performed a similar increment with increase of frequency, and these increments were unrelated with the content of poplar fiber in printed biocomposite. This is probably explained by the dominant effect of PLA in the biocomposite with few poplar fibers $(<9 \%)$ at a high frequency (Yin et al. 2018). Through addition of the poplar fiber, the complex viscosity $\left(\eta^{*}\right)$ of the printed biocomposite decreased at low frequency $(0.1$ to $100 \mathrm{~Hz})$ and remained at high frequency 
(>100 Hz) (Fig. 4b), except for the situation at 1\% poplar fiber, where the $\eta^{*}$ was higher than that of pure PLA due to the favorable bonding that formed between the poplar fiber and PLA matrix (Sang et al. 2019). However, the interaction between PLA molecules was interrupted by the uneven dispersed poplar fiber $(>1 \%)$, resulting in a low $\eta^{*}$ value of the biocomposite.

By considering the mechanical properties of the printed biocomposites above, the poplar fiber of $5 \%$ was chosen to print the biocomposite. Further investigation focused on the effect of printing parameters on the properties of the biocomposite.

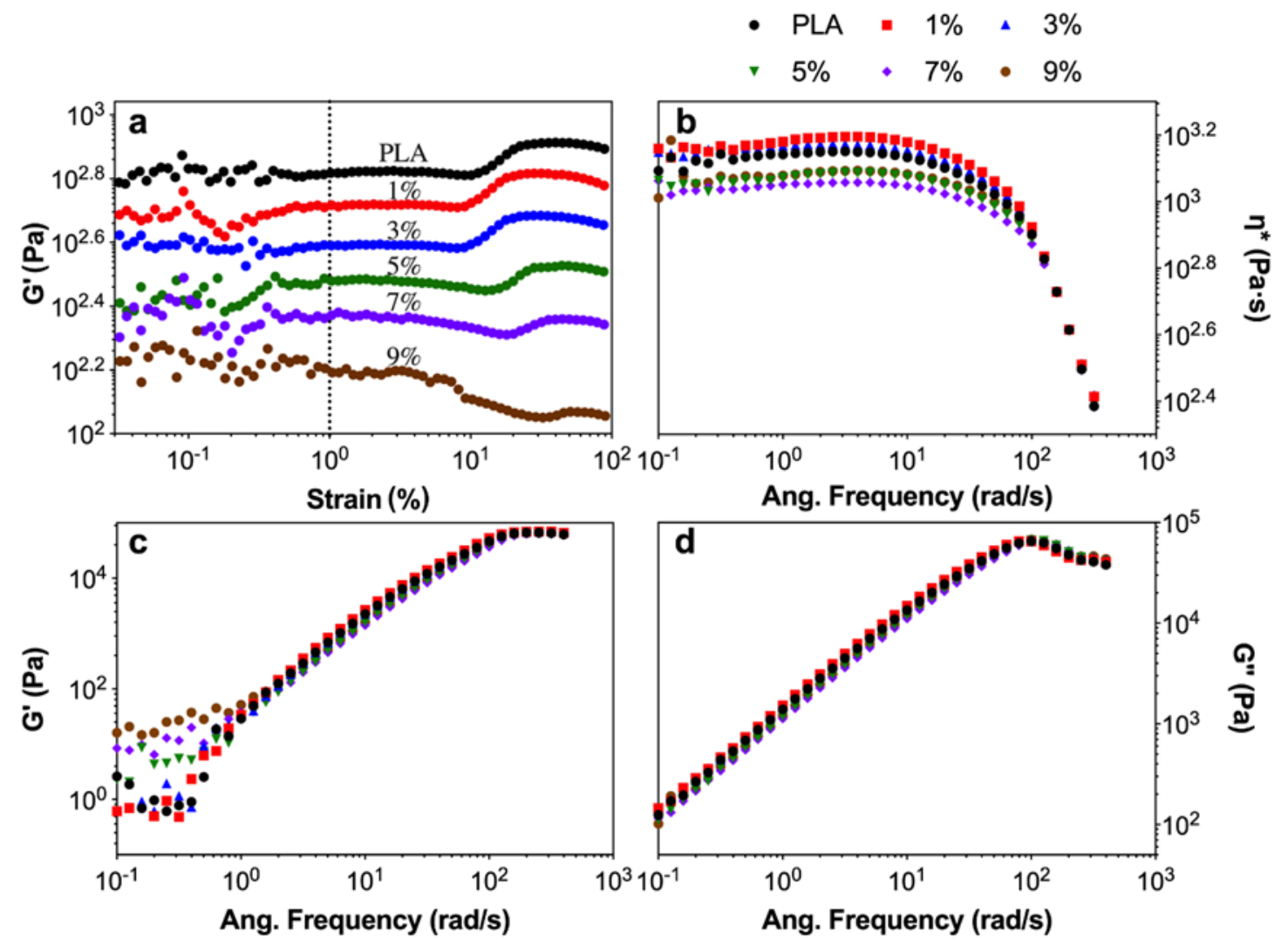

Fig. 4. Dynamic strain sweeps at $190^{\circ} \mathrm{C}$ with an angular frequency of $6.283 \mathrm{rad} / \mathrm{s}$, a; complex viscosity $\eta^{*}$, b; storage modulus G', c; and loss modulus $G^{\prime \prime}, \mathrm{d}$ of 3D-printed biocomposites

\section{Effect of Printing Temperature on the Properties of Printed Biocomposites}

When the printing temperature increased, the flexural strength and modulus first increased and then decreased, and the optimal flexural properties were obtained at $220{ }^{\circ} \mathrm{C}$. This behavior can be attributed to the fusing state of the printed filaments from the printing nozzle, where the filament had an incomplete fusion under low temperature, resulting in voids to be generated between printed filaments, as shown in Fig. 5b. However, better fusion was formed at $220^{\circ} \mathrm{C}$, which induced preferable adhesion between printed filaments (Fig. 5c); therefore, higher flexural properties were obtained. At a high printing temperature $\left(>220{ }^{\circ} \mathrm{C}\right)$, the biocomposite degraded and the voids were gradually reduced (Fig. 5d), resulting in decreased flexural properties and increased density of the biocomposites, respectively (Feng et al. 2017). 

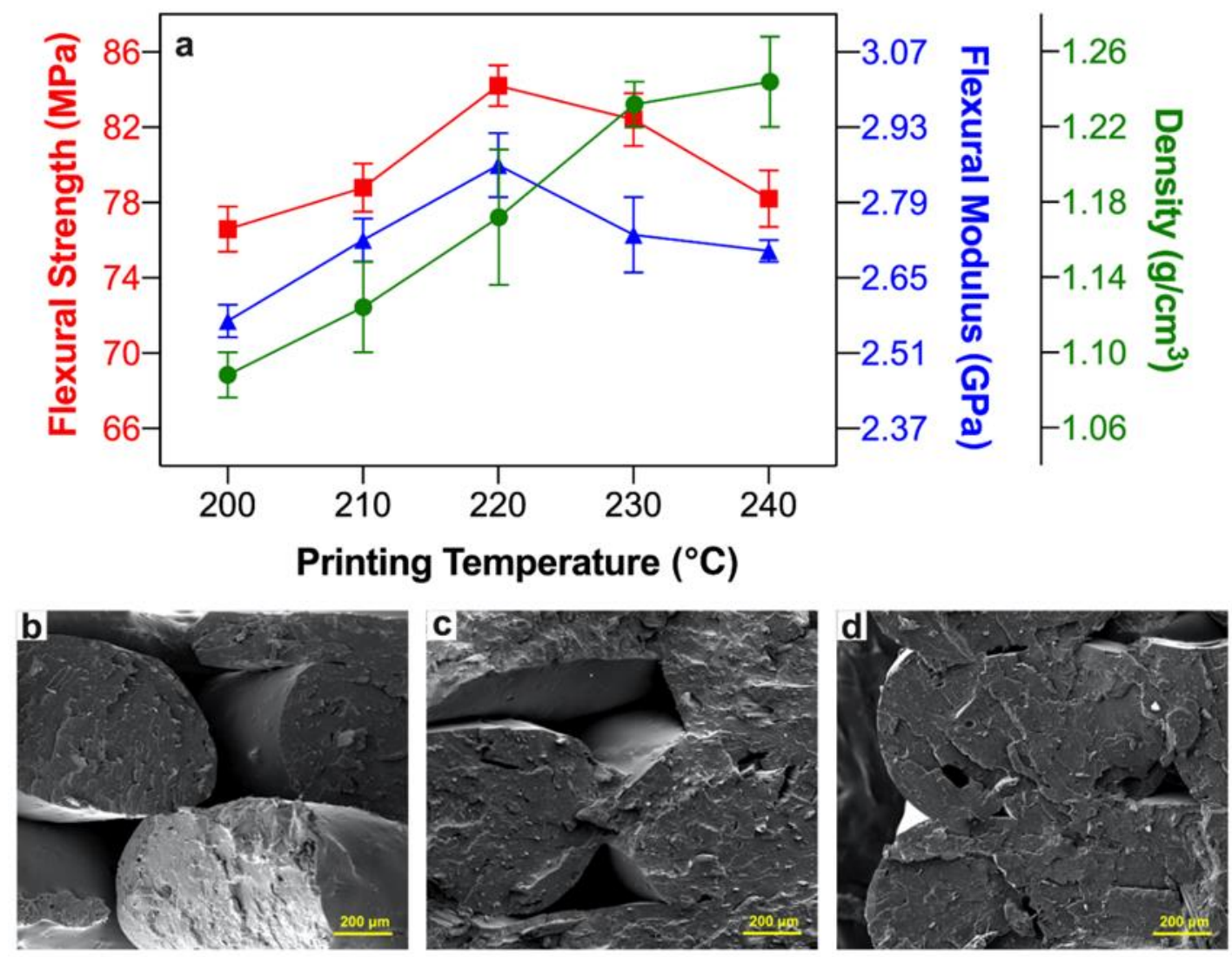

Fig. 5. The density and flexural properties, $a$; and morphologies $\left(b=200^{\circ} \mathrm{C} ; \mathrm{c}=220^{\circ} \mathrm{C} ; \mathrm{d}=\right.$ $240{ }^{\circ} \mathrm{C}$ ) of biocomposites 3D-printed at different printing temperatures

\section{Effect of Printing Speed on the Properties of Printed Biocomposites}

In contrast to the printing temperature, the printing speed had a negative effect on the flexural properties and density of the biocomposite, in which the flexural properties and density decreased when the printing speed was increased (Fig. 6). This was caused by the mismatch of the printing speed with the feeding speed, with which the printed filaments could not generate efficient inter-adhesion during printing and led to an increase in voids when the printing speed increased (Figs. 6b and 6c), resulting in decreased flexural properties and density (Yang and Yeh 2020). Hence, the printing efficiency, thermal stability of the fused filament in nozzle, and printing stability of the printer should be comprehensively considered when a suitable printing speed is selected.

\section{Effect of Printing Layer Thickness on the Properties of Printed Biocomposites}

Similarly, the flexural properties and the density of the biocomposite decreased when the layer thickness was increased (Fig. 7). The flexural strength decreased $42 \%$ at a layer thickness of $0.5 \mathrm{~mm}$ compared to that of $0.1 \mathrm{~mm}$. This can be attributed to the increased voids between printed filaments as the layer thickness increased (Figs. 7b and 7c), which generated inefficient adhesion between the printed filaments and induced weak boding in the layers of the biocomposite. In addition, the high layer thickness produced uneven temperature distribution in the printed layer, resulting in a further decrease in the bonding in the layers and of the properties of the biocomposite (Liu et al. 2015). 

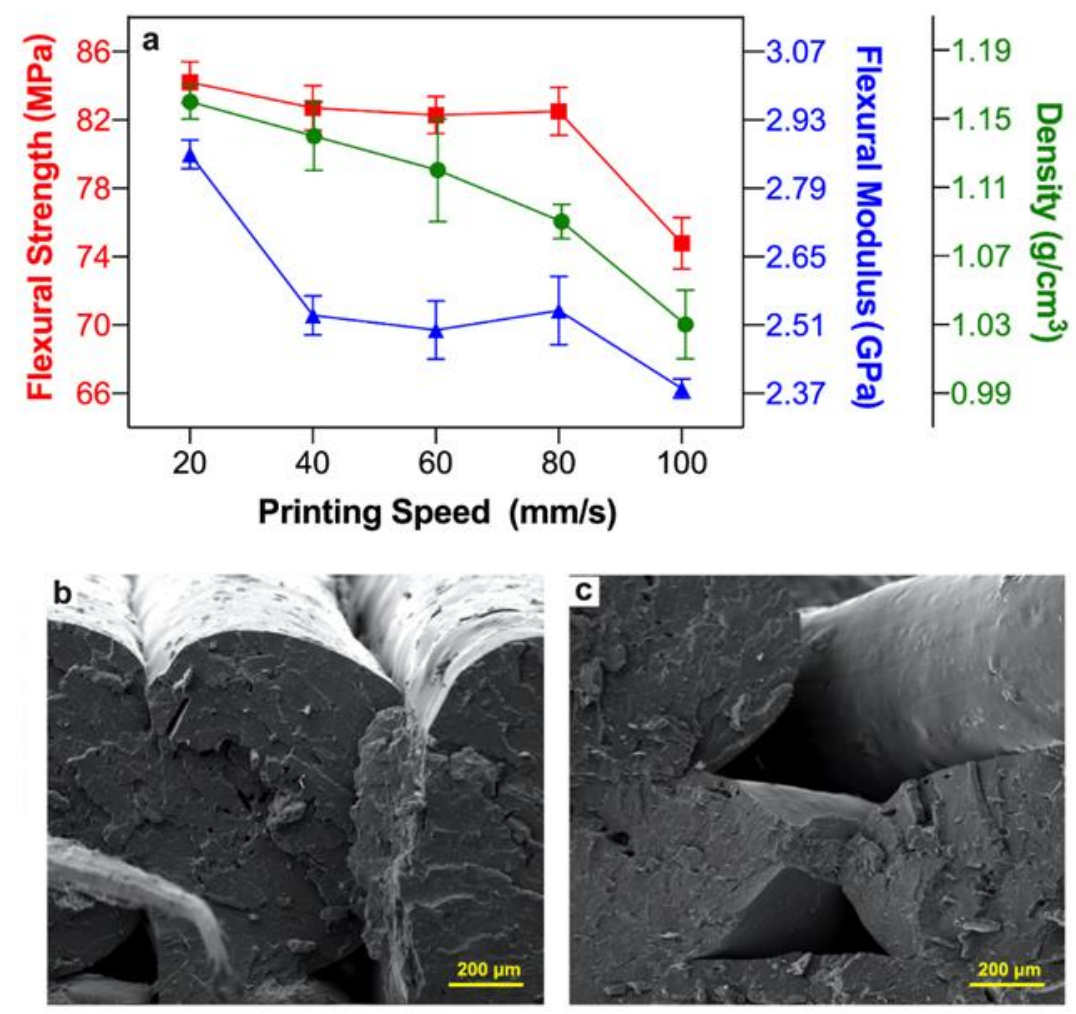

Fig. 6. The density and flexural properties, $a$; and morphologies $(b=20 \mathrm{~mm} / \mathrm{s} ; \mathrm{c}=60 \mathrm{~mm} / \mathrm{s})$ of biocomposites 3D-printed by different printing speeds
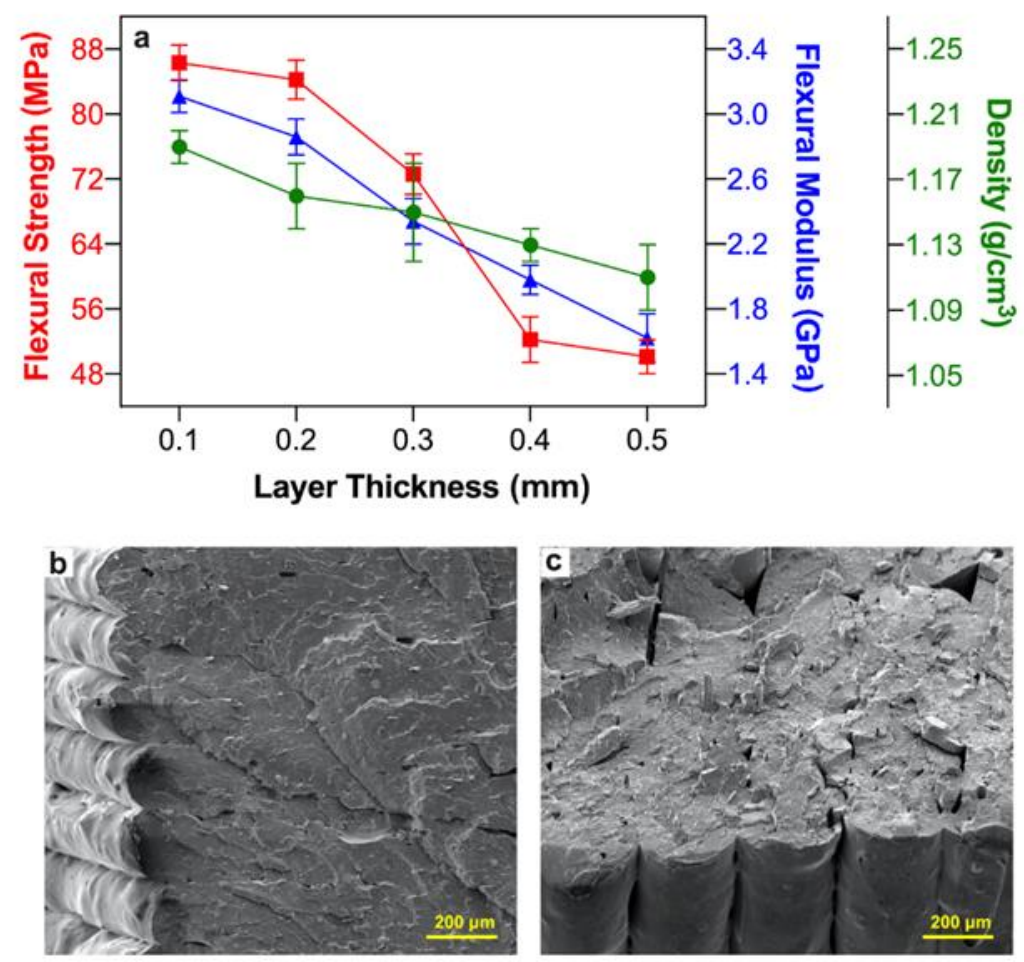

Fig. 7. The density and flexural properties, $a$; and morphologies $(b=0.2 \mathrm{~mm} ; c=0.3 \mathrm{~mm})$ of biocomposites 3D-printed using different layer thickness 


\section{Effect of Printing Orientation on the Properties of Printed Biocomposites}

The printing temperature, speed, and layer thickness at $220{ }^{\circ} \mathrm{C}, 40 \mathrm{~mm} / \mathrm{s}$, and $0.2 \mathrm{~mm}$, respectively, were selected based on the results obtained above to investigate the effect of printing orientations on the properties of the biocomposite. As shown in Fig. 8, four printing orientations were used and the tensile and flexural properties of the biocomposite were measured. The tensile strength, elongation, and flexural strength obtained maximum values with longitudinal stripe and minimum value with transversal stripe (Figs. 8e to 8g). However, the optimal flexural modulus was observed at transversal and longitudinal stripes (Fig. 8h). The properties of the biocomposite with a $45^{\circ}$ cross was higher than those with a $90^{\circ}$ cross, except for their comparable flexural modulus.
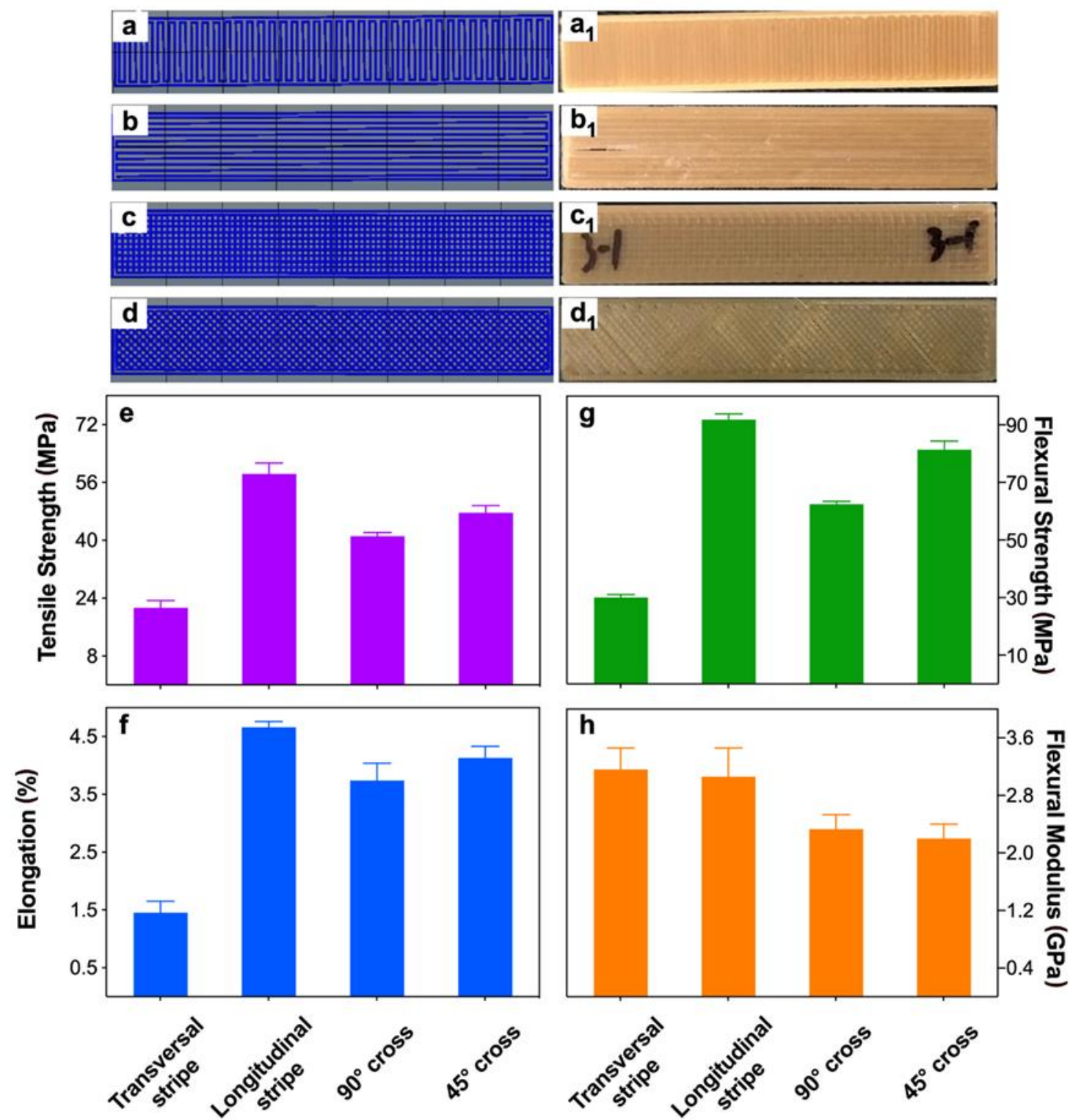

Fig. 8. 3D-printed models (a to d), samples ( $a_{1}$ to $\left.d_{1}\right)$, and their mechanical properties $(e=$ tensile strength; $f=$ elongation; $g$ = flexural strength; $h=$ flexural modulus) with different printing orientations ( $a$ and $a_{1}$, transversal stripe; $b$ and $b_{1}$, longitudinal stripe; $c$ and $c_{1}, 90^{\circ}$ cross; $d$ and $\mathrm{d}_{1}, 45^{\circ}$ cross) 
According to the mechanical properties of the printed biocomposites, as shown in Fig. 8, the printing orientation at longitudinal direction is preferable to fabricate the product when high mechanical strength is considered. However, the application conditions should be considered when a suitable printing parameter is chosen for the printed product. For example, the flowerpot in Fig. 9 needs good appearance and breathability rather than high mechanical properties in realistic applications. Therefore, a smooth surface and suitable porosity of the printed biocomposite should be produced by selecting a high printing speed and low layer thickness during 3D printing. Compared with the commercial polypropylene flowerpot (Fig. 9a), the printed flowerpot is biodegradable and eco-friendly, and it will promote the growing of the plant due to its adjustable breathability derived from the porosity of the printed biocomposites, as shown in the morphologies of biocomposite described above.

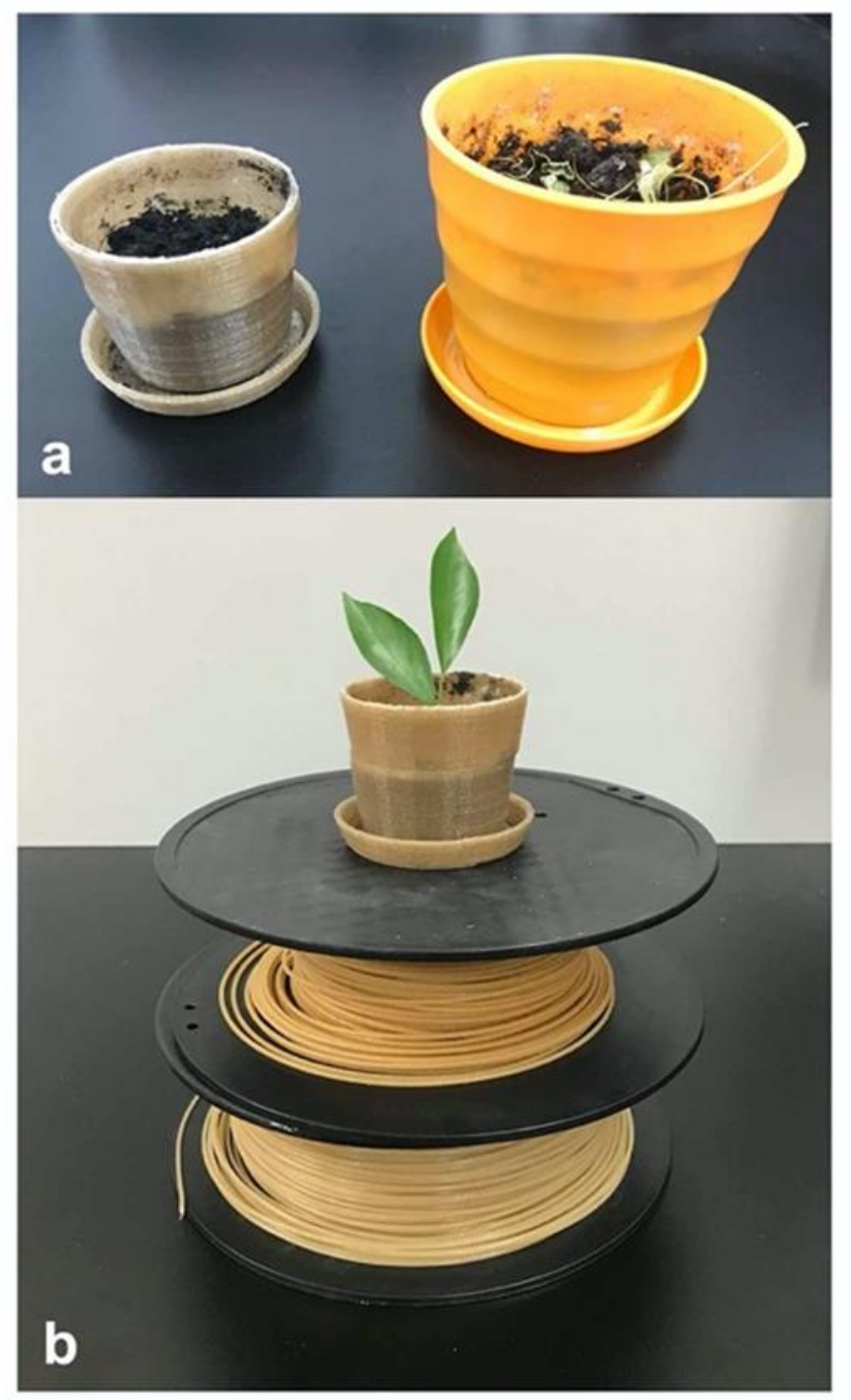

Fig. 9. 3D-printed biodegradable flowerpot with the poplar fiber/PLA biocomposite; a, comparison of biodegradable flowerpot (left) with a commercial polypropylene flowerpot (right) and $b$, the printing filament and flowerpot with a plant in it 


\section{CONCLUSIONS}

1. The application of poplar fiber reinforced polylactic acid (PLA) biocomposite in the 3D printing was investigated using various poplar fiber contents. The printed biocomposite with $5 \%$ poplar fiber achieved optimal mechanical properties. The printing parameters of the 5\% poplar fiber/PLA biocomposite, including printing temperature, speed, and layer thickness, were further optimized.

2. The printing temperature, speed, and layer thickness at $220{ }^{\circ} \mathrm{C}, 40 \mathrm{~mm} / \mathrm{s}$, and $0.2 \mathrm{~mm}$, respectively, were applied to print biocomposites with superior mechanical properties when a longitudinal orientation was used. In addition, the density of the printed biocomposites had an obvious correlation with the mechanical strength when different printing parameters were applied. Diverse contents of void in the printed biocomposites were induced by applying various printing parameters. At an optimal printing temperature, the smaller voids induced higher density and resulted in higher mechanical strength.

3. However, the application situation of the 3D-printed biocomposite should be thoroughly considered when choosing suitable printing parameters to efficiently and economically fabricate the product applied in different conditions, such as strengthoriented and appearance-oriented situations.

\section{ACKNOWLEDGMENTS}

The authors acknowledge the financial support from the Natural Science Foundation of Jiangsu Province (Grant No. BK20200779), the Natural Science Research Project of Jiangsu Colleges and Universities (Grant No. 19KJB220004), and the Youth Science and Technology Innovation Fund of Nanjing Forestry University (Grant No. CX2019015). Additionally, Dr. Yang thanks the China Scholarship Council for the research funding at the University of Laval (Grant No. 201606600031).

\section{REFERENCES CITED}

ASTM D638-14 (2014). "Standard test method for tensile properties of plastics," ASTM International, West Conshohocken, PA, USA.

ASTM D638-17 (2017). "Standard test methods for flexural properties of unreinforced and reinforced plastics and electrical insulating materials," ASTM International, West Conshohocken, PA, USA.

Ayrilmis, N. (2018). "Effect of layer thickness on surface properties of 3D printed materials produced from wood flour/PLA filament," Polymer Testing 71, 163-166. DOI: 10.1016/j.polymertesting.2018.09.009

Bhagia, S., Lowden, R. R., Erdman, D., III, Rodriguez, M., Jr., Haga, B. A., Solano, I. R. M., Gallego, N. C., Pu, Y., Muchero, W., Kunc, V., and Ragauskas, A. J. (2020). "Tensile properties of 3D-printed wood-filled PLA materials using poplar trees," Applied Materials Today 21. DOI: 10.1016/j.apmt.2020.100832

Chacón, J. M., Caminero, M. A., Núñez, P. J., García-Plaza, E., García-Moreno, I., and Reverte, J. M. (2019). “Additive manufacturing of continuous fibre reinforced 
thermoplastic composites using fused deposition modelling: Effect of process parameters on mechanical properties," Composites Science and Technology 181, Article ID 107688. DOI: 10.1016/j.compscitech.2019.107688

Chougan, M., Ghaffar, S. H., Jahanzat, M., Albar, A., Mujaddedi, N., and Swash, R. (2020). "The influence of nano-additives in strengthening mechanical performance of 3D printed multi-binder geopolymer composites," Construction and Building Materials 250, Article ID 118928. DOI: 10.1016/j.conbuildmat.2020.118928

Compton, B. G., and Lewis, J. A. (2014). “3D-printing of lightweight cellular composites," Advanced Materials 26(34), 5930-5935. DOI:

10.1002/adma.201401804

Dong, Y., Milentis, J., and Pramanik, A. (2018). "Additive manufacturing of mechanical testing samples based on virgin poly (lactic acid) (PLA) and PLA/wood fibre composites," Advances in Manufacturing 6(1), 71-82. DOI: 10.1007/s40436-0180211-3

Feng, X., Yang, Z., Rostom, S. S. H., Dadmun, M., Xie, Y., and Wang, S. (2017). "Structural, mechanical, and thermal properties of 3D printed L-CNC/acrylonitrile butadiene styrene nanocomposites," Journal of Applied Polymer Science 134(31), Article ID 45082. DOI: 10.1002/app.45082

Filgueira, D., Holmen, S., Melbø, J. K., Moldes, D., Echtermeyer, A. T., and ChingaCarrasco, G. (2017). "Enzymatic-assisted modification of thermomechanical pulp fibers to improve the interfacial adhesion with poly(lactic acid) for 3D printing," $A C S$ Sustainable Chemistry \& Engineering 5(10), 9338-9346. DOI:

10.1021/acssuschemeng.7b02351

Ghaffar, S. H., Al-Kheetan, M., Ewens, P., Wang, T., and Zhuang, J. (2020). "Investigation of the interfacial bonding between flax/wool twine and various cementitious matrices in mortar composites," Construction and Building Materials 239, Article ID 117833. DOI: 10.1016/j.conbuildmat.2019.117833

Ghaffar, S. H., Corker, J., and Fan, M. (2018). "Additive manufacturing technology and its implementation in construction as an eco-innovative solution," Automation in Construction 93, 1-11. DOI: 10.1016/j.autcon.2018.05.005

Guo, S.-Z., Heuzey, M.-C., and Therriault, D. (2014). "Properties of polylactide inks for solvent-cast printing of three-dimensional freeform microstructures," Langmuir 30(4), 1142-1150. DOI: 10.1021/la4036425

Hinchcliffe, S. A., Hess, K. M., and Srubar III, W. V. (2016). "Experimental and theoretical investigation of prestressed natural fiber-reinforced polylactic acid (PLA) composite materials," Composites Part B: Engineering 95, 346-354. DOI: 10.1016/j.compositesb.2016.03.089

Kain, S., Ecker, J. V., Haider, A., Musso, M., and Petutschnigg, A. (2020). "Effects of the infill pattern on mechanical properties of fused layer modeling (FLM) 3D printed wood/polylactic acid (PLA) composites," European Journal of Wood and Wood Products 78(1), 65-74. DOI: 10.1007/s00107-019-01473-0

Le Duigou, A., Castro, M., Bevan, R., and Martin, N. (2016). "3D printing of wood fibre biocomposites: From mechanical to actuation functionality," Materials \& Design 96, 106-114. DOI: 10.1016/j.matdes.2016.02.018

Li, Y., Yu, J., and Guo, Z.-X. (2003). "The influence of interphase on nylon-6/nano-SiO 2 composite materials obtained from in situ polymerization," Polymer International 52(6), 981-986. DOI: 10.1002/pi.1173

Liu, J., Sun, L., Xu, W., Wang, Q., Yu, S., and Sun, J. (2019). “Current advances and 
future perspectives of 3D printing natural-derived biopolymers," Carbohydrate Polymers 207, 297-316. DOI: 10.1016/j.carbpol.2018.11.077

Liu, K., Yang, Z., and Takagi, H. (2014). "Anisotropic thermal conductivity of unidirectional natural abaca fiber composites as a function of lumen and cell wall structure," Composite Structures 108, 987-991. DOI:

10.1016/j.compstruct.2013.10.036

Liu, X., Li, S., Liu, Z., Zheng, X., Chen, X., and Wang, Z. (2015). “An investigation on distortion of PLA thin-plate part in the FDM process," International Journal of Advanced Manufacturing Technology 79(5), 1117-1126. DOI: 10.1007/s00170-0156893-9

Murphy, C. A., and Collins, M. N. (2018). "Microcrystalline cellulose reinforced polylactic acid biocomposite filaments for 3D printing," Polymer Composites 39(4), 1311-1320. DOI: 10.1002/pc.24069

Nguyen, N. A., Bowland, C. C., and Naskar, A. K. (2018). "General method to improve 3D-printability and inter-layer adhesion in lignin-based composites," Applied Materials Today 12, 138-152. DOI: 10.1016/j.apmt.2018.03.009

Oladapo, B. I., Ismail, S. O., Zahedi, M., Khan, A., and Usman, H. (2020). “3D printing and morphological characterisation of polymeric composite scaffolds," Engineering Structures 216, Article ID 110752. DOI: 10.1016/j.engstruct.2020.110752

Papon, E. A., and Haque, A. (2018). "Tensile properties, void contents, dispersion and fracture behaviour of 3D printed carbon nanofiber reinforced composites," Journal of Reinforced Plastics and Composites 37(6), 381-395. DOI: 10.1177/0731684417750477

Sang, L., Han, S., Li, Z., Yang, X., and Hou, W. (2019). "Development of short basalt fiber reinforced polylactide composites and their feasible evaluation for 3D printing applications," Composites Part B: Engineering 164, 629-639. DOI: 10.1016/j.compositesb.2019.01.085

Spinelli, G., Lamberti, P., Tucci, V., Ivanova, R., Tabakova, S., Ivanov, E., Kotsilkova, R., Cimmino, S., Di Maio, R., and Silvestre, C. (2019). "Rheological and electrical behaviour of nanocarbon/poly(lactic) acid for 3D printing applications," Composites Part B: Engineering 167, 467-476. DOI: 10.1016/j.compositesb.2019.03.021

Tian, X., Liu, T., Wang, Q., Dilmurat, A., Li, D., and Ziegmann, G. (2017). "Recycling and remanufacturing of 3D printed continuous carbon fiber reinforced PLA composites," Journal of Cleaner Production 142(Part 4), 1609-1618. DOI: 10.1016/j.jclepro.2016.11.139

Tian, X., Liu, T., Yang, C., Wang, Q., and Li, D. (2016). "Interface and performance of 3D printed continuous carbon fiber reinforced PLA composites," Composites Part A: Applied Science and Manufacturing 88, 198-205. DOI:

10.1016/j.compositesa.2016.05.032

Wang, Z., Xu, J., Lu, Y., Hu, L., Fan, Y., Ma, J., and Zhou, X. (2017). "Preparation of 3D printable micro/nanocellulose-polylactic acid (MNC/PLA) composite wire rods with high MNC constitution," Industrial Crops and Products 109, 889-896. DOI: 10.1016/j.indcrop.2017.09.061

Xiao, X., Chevali, V. S., Song, P., He, D., and Wang, H. (2019). "Polylactide/hemp hurd biocomposites as sustainable 3D printing feedstock," Composites Science and Technology 184, Article ID 107887. DOI: 10.1016/j.compscitech.2019.107887

Xu, W., Pranovich, A., Uppstu, P., Wang, X., Kronlund, D., Hemming, J., Öblom, H., Moritz, N., Preis, M., Sandler, N., et al. (2018). "Novel biorenewable composite of 
wood polysaccharide and polylactic acid for three dimensional printing," Carbohydrate Polymers 187, 51-58. DOI: 10.1016/j.carbpol.2018.01.069

Yang, F., Zeng, J., Long, H., Xiao, J., Luo, Y., Gu, J., Zhou, W., Wei, Y., and Dong, X. (2020). "Micrometer copper-zinc alloy particles-reinforced wood plastic composites with high gloss and antibacterial properties for 3D printing," Polymers 12(3), Article Number 621. DOI: 10.3390/polym12030621

Yang, T.-C., and Yeh, C.-H. (2020). "Morphology and mechanical properties of 3D printed wood fiber/polylactic acid composite parts using fused deposition modeling (FDM): The effects of printing speed," Polymers 12(6), Article Number 1334. DOI: 10.3390/polym12061334

Yang, Z., Bi, H., Bi, Y., Rodrigue, D., Xu, M., and Feng, X. (2019). “Comparison between polyethylene glycol and tributyl citrate to modify the properties of wood fiber/polylactic acid biocomposites," Polymer Composites 40(4), 1384-1394. DOI: $10.1002 / \mathrm{pc} .24872$

Yang, Z., Feng, X., Xu, M., and Rodrigue, D. (2020). "Properties of poplar fiber/PLA composites: Comparison on the effect of maleic anhydride and KH550 modification of poplar fiber," Polymers 12(3), Article Number 729. DOI: 10.3390/polym12030729

Yin, X., Hewitt, D. R. O., Quah, S. P., Zheng, B., Mattei, G. S., Khalifah, P. G., Grubbs, R. B., and Bhatia, S. R. (2018). "Impact of stereochemistry on rheology and nanostructure of PLA-PEO-PLA triblocks: Stiff gels at intermediate L/D-lactide ratios," Soft Matter 14(35), 7255-7263. DOI: 10.1039/c8sm01559g

Yu, S., Hwang, Y. H., Hwang, J. Y., and Hong, S. H. (2019). "Analytical study on the 3Dprinted structure and mechanical properties of basalt fiber-reinforced PLA composites using X-ray microscopy," Composites Science and Technology 175, 18-27. DOI: 10.1016/j.compscitech.2019.03.005

Zeng, C., Liu, L., Bian, W., Liu, Y., and Leng, J. (2020). “4D printed electro-induced continuous carbon fiber reinforced shape memory polymer composites with excellent bending resistance," Composites Part B: Engineering 194, Article ID 108034. DOI: 10.1016/j.compositesb.2020.108034

Zhao, X. G., Hwang, K.-J., Lee, D., Kim, T., and Kim, N. (2018). "Enhanced mechanical properties of self-polymerized polydopamine-coated recycled PLA filament used in 3D printing," Applied Surface Science 441, 381-387. DOI:

10.1016/j.apsusc.2018.01.257

Article submitted: January 11, 2021; Peer review completed: February 21, 2021; Revised version received and accepted: February 22, 2021; Published: February 24, 2021.

DOI: 10.15376/biores.16.2.2774-2788 